\title{
SiMUlaCión DE LA RESPUESTA AL DISTURBIO DEL BOSQUE MESÓFILO MEDIANTE UN AUTÓMATA CELULAR
}

\author{
Francisco Javier Díaz-Perea ${ }^{1,2,3}$ y Miguel Equihua ${ }^{1}$ \\ 'Red de Ambiente y Sustentabilidad, Instituto de Ecología, A.C., Xalapa, Veracruz, México \\ ${ }^{2}$ Gerencia de Protección Ambiental, Comisión Federal de Electricidad, Distrito Federal, México \\ ${ }^{3}$ Autor para la correspondencia: diazperea@gmail.com
}

\begin{abstract}
Resumen: El bosque mesófilo enfrenta disturbios de origen natural y antrópico que amenazan su persistencia; por ello estudiar su respuesta al disturbio es importante para explorar su capacidad de soportar perturbaciones y su relación con la diversidad funcional. Este estudio tuvo el propósito de detectar los patrones estructurales que emergen a largo plazo en la comunidad de árboles del bosque mesófilo, simulando su dinámica espacio-temporal con un autómata celular. La modelación se basó en tipos de regeneración que se definieron combinando atributos de regeneración de las especies arbóreas. Se construyó un autómata celular, las reglas de operación del simulador se basaron en los procesos biológicos relacionados con la regeneración de las especies y en la densidad de árboles alrededor de cada celda. Se simularon tres tratamientos: sin disturbio, disturbio ligero y disturbio severo. Las comunidades tuvieron la siguiente evolución: en el tratamiento sin disturbio creció la abundancia de los tipos con perfil competitivo, mientras que se redujo la de los tipos con perfil colonizador; y disminuyó el número de tipos de regeneración. La comunidad sujeta a disturbio ligero se recuperó inmediatamente; mientras que en la que se sujetó al disturbio severo, la comunidad, y los bancos de semillas y plántulas en el área perturbada se recuperaron lentamente. La huella del disturbio permaneció visible a lo largo del periodo simulado. Los patrones de colonización de las áreas perturbadas sugieren que existe una complementariedad de respuesta al disturbio de los tipos de regeneración.

Palabras clave: atributo, comunidad, tipo de regeneración, vecindario.
\end{abstract}

\begin{abstract}
The cloud forest is facing natural and human-induced disturbances that threaten their persistence; so, studying how this ecosystem responds to disturbance is important to explore its ability to withstand stress based on its functional diversity. This study aimed to detect functional patterns that emerge in a cloud forest community, simulating the spatio-temporal dynamics using a cellular automaton. Modeling was based on regeneration types that were defined combining regeneration traits of tree species in a previous research developed at La Cortadura, Veracruz. We structured a cellular automaton, the operation rules were based on key biological processes involved in species regeneration and the density of trees around each cell. We simulated three treatments: no-disturbance, light disturbance and severe disturbance. The communities evolved as follows: on no-disturbed treatment, types with competitive profile increased their abundance, while the abundance of types with pioneer profile decreased. In light-disturbed treatment, the community immediately recovered, while in severe disturbance treatment, the community, and seed and seedlings banks recovered slowly and a disturbance imprint remained throughout the simulation. Colonization patterns of disturbed areas suggest a complementary response to the disturbance of regeneration types.
\end{abstract}

Keywords: community, neighbourhood, regeneration type, trait.

$\mathbf{E}$ 1 bosque mesófilo es uno de los ecosistemas más amenazados en el mundo y su conservación es de alta prioridad, por su importancia en el mantenimiento de los ciclos hidrológicos y de nutrientes, y por su gran diversidad (Bruijnzeel, 2001). En México, el bosque mesófilo alberga un gran número de endemismos y entre 10 y $12 \%$ de la flora del país a pesar de que ocupa menos de $1 \%$ del territorio nacional (Rzedowski, 1978, Challenger, 1998). Se distribuye común- mente en zonas de niebla en regiones de transición entre tipos climáticos tropicales y templados. Es un ecosistema frágil, debido a que depende principalmente del microclima que es mantenido por el propio bosque (Challenger, 1988). Estos bosques se encuentran sometidos a diversos tipos de disturbios naturales y de origen antrópico que amenazan su persistencia y han causado cambios en su estructura y composición, entre otros impactos (Leija-Loredo et al., 2011; 
Toledo-Aceves et al., 2011). Por esta razón, es importante estudiar si estos cambios afectan a los controles bióticos (diversidad funcional) relacionados con la capacidad del bosque mesófilo para soportar disturbios (resiliencia).

La resiliencia ha sido definida como la capacidad de un ecosistema de absorber disturbios y reorganizarse de forma tal que pueda mantener esencialmente la misma estructura, funcionamiento y mecanismos de auto-regulación (Walker et al., 1999). En los ecosistemas, una característica estructural generadora de resiliencia es la diversidad y la redundancia de sus grupos funcionales (Peterson et al., 1998; Walker et al., 1999; Naeem et al., 2002).

Los disturbios, definidos como la destrucción o remoción de biomasa que ocurre irregularmente (Shea et al., 2004), son a la vez una causa de mortalidad para algunos individuos y una oportunidad para que otros puedan establecerse. Tienen una gran influencia en la estructura y composición de las comunidades, y ayudan a explicar la heterogeneidad espacial de los ecosistemas (White y Jentsch, 2001). La frecuencia y severidad, entre otros atributos, son características de los disturbios; la severidad es una medida del daño que la fuerza perturbadora causa a la comunidad (Sousa, 1984).

La recuperación de la vegetación después de un disturbio es un proceso intrincado, los cambios direccionales en la comunidad de plantas se conocen como sucesión secundaria, la cual es un proceso influido por la biología de las especies, las interacciones entre las especies y entre los componentes bióticos y abióticos, y por eventos estocásticos (Guariguata y Ostertag, 2001). Los bancos de brotes, semillas y plántulas, así como las semillas dispersadas desde sitios cercanos, son las fuentes para la regeneración de los bosques después de un disturbio (Klimešová y Klimeš, 2007).

La severidad de los disturbios influye en la recuperación de la vegetación por el impacto que se provoca a los bancos de brotes, semillas y plántulas, así como por el tamaño del área impactada, que se relaciona con la distancia del sitio perturbado a la fuente más cercana de propágulos (Rydgren et al., 2004). En disturbios ligeros, la vegetación se recupera rápidamente a partir del retoño de algunos individuos y de los bancos de plántulas y semillas que persistieron. Por el contrario, en disturbios severos (que eliminan a todos los individuos adultos y a los bancos de plántulas y semillas) la recuperación de la vegetación es lenta, ya que la colonización depende de los propágulos provenientes de fuentes aledañas.

Una perspectiva prometedora para el estudio de procesos espacial y temporalmente dinámicos a largo plazo, como lo es la regeneración de la vegetación, es la modelación espacialmente explícita (Zavala et al., 2006). Ésta permite experimentar en "laboratorios virtuales" el desarrollo de sistemas complejos. En los últimos años se han hecho grandes avances en la modelación de sistemas complejos (Fernández-Quiroga, 2005). El producto de la modelación son escenarios hipotéticos, sugerentes del desarrollo esperable de un sistema bajo condiciones pre-establecidas. Mediante el análisis de estos escenarios es posible explorar los cambios que bajo determinadas condiciones podrían presentarse en el sistema y proponer hipótesis explicativas de los cambios y de los patrones de distribución espacial generados.

Los autómatas celulares (AC) son un tipo de modelación que simula el comportamiento de sistemas complejos basados en reglas locales. Son una alternativa para modelar una amplia variedad de sistemas físicos, humanos, biológicos y ecológicos (Hogeweg, 1988; Batty, 2005). En el estudio de sistemas ambientales se han utilizado AC para simular la dinámica de cambio de uso de suelo (Soares-Filho et al., 2002), la distribución espacial de plantas (Carey, 1996), la dinámica de poblaciones (Moloney y Levin, 1996), la dinámica de la vegetación (Ellison y Bedford, 1995; Balzter et al., 1998; Colasanti et al., 2001, Aassine y El Jaï, 2002) y la dinámica de regeneración del bosque (Ramírez-Angulo et al., 2006).

Con el propósito de estudiar la respuesta al disturbio en un bosque mesófilo se construyó un AC para revelar los principales patrones estructurales que emergen a largo plazo en la comunidad de árboles después de someterla a disturbios de diferente intensidad. La modelación utilizó a tipos funcionales, los cuales son agrupaciones no filogenéticas de especies con atributos biológicos comunes y que se desempeñan de forma similar en el ecosistema (Lavorel et al., 1997; Díaz et al., 1999). Con este enfoque la diversidad de especies se reduce a unas cuantas unidades funcionales, lo cual simplifica la complejidad del bosque mesófilo y facilita la aplicación de las herramientas de modelación.

Los tipos funcionales, denominados en este estudio tipos de regeneración, se definieron utilizando atributos de regeneración de las plantas relacionados con los procesos clave para la persistencia de las especies (Pausas y Lavorel, 2003): dispersión de las semillas (modos anemócoro, baro-endozoocoro), persistencia temporal de los propágulos (capacidad de formar banco de semillas o de plántulas) y respuesta a la luz de las plántulas (tolerancia a la sombra). Cada tipo de regeneración agrupó a las especies que tienen una combinación específica de atributos y representa así una estrategia de regeneración (ver Díaz-Perea et al., 2014 para mayores detalles de la clasificación funcional).

En el AC desarrollado se diferenciaron tres subsistemas: la comunidad de árboles y los bancos de plántulas y los bancos de semillas. Este tratamiento refleja la importancia que los dos últimos subsistemas desempeñan en la recuperación de la vegetación, ya que almacenan a las estructuras a partir de las cuales puede renovarse la comunidad.

Con el AC se simuló la dinámica del bosque sin la ocurrencia de disturbios (i.e. considerando a la mortalidad natural de los árboles como el único factor que los elimina de la comunidad). A partir de esta línea base se aplicaron para contrastar dos intensidades de disturbio: baja y gran severidad. 


\section{Materiales y métodos}

Formulación del modelo: generalidades y estados discretos. En la modelación de la dinámica de una comunidad de plantas mediante un $\mathrm{AC}$, el espacio se representa como una rejilla en la que cada celda puede estar vacía u ocupada por un individuo. En este estudio, los individuos pertenecen a un tipo de regeneración, los cuales representan los estados del sistema.

En el AC la dinámica se genera porque los diferentes tipos compiten por ocupar las celdas disponibles. Para que un individuo del tipo $i$ prospere en una celda vacía se requiere que dicha celda sea alcanzada por propágulos provenientes de alguna celda aledaña ocupada por un adulto de su tipo y de que se establezca. La dispersión de las semillas alrededor de cada individuo adulto es un proceso importante que marca diferencias en la habilidad de colonización potencial que tienen los diferentes tipos de regeneración en la comunidad.

En un enfoque de modelación de tiempo discreto, todas las celdas pueden o no cambiar de estado simultáneamente, ya que los AC usualmente son síncronos. El destino de cada celda depende de su vecindario y de la función de transición correspondiente (Plotnick y Gardner, 2002). Las reglas de transición pueden ser determinísticas o estocásticas.
El AC se desarrolló en una rejilla de cuadrículas ( $n$ filas por $m$ columnas) y se utilizó una plantilla tipo Moore (una celda central y ocho adyacentes) para representar el vecindario de las celdas. La rejilla se dividió en tres subsistemas de igual dimensión (50 filas por 50 columnas) que representan a la comunidad de árboles, el banco de semillas y el banco de plántulas, los dos últimos subsistemas son las fuentes in situ para la regeneración de la comunidad de árboles. Esta estrategia para simular la regeneración del bosque permite que la simulación de la dinámica de los subsistemas se realice en forma independiente, lo cual tiene la ventaja de facilitar el control de los componentes y procesos propios de cada subsistema. Además, la ubicación espacial de las celdas en cada subsistema es la misma y puede realizarse simultáneamente la actualización del estado de las celdas en todos los subsistemas.

Se simularon ocho tipos de regeneración que resultaron de la combinación de los siguientes atributos de regeneración: el modo de dispersión (anemócoro o /baro- endozoocoro), la persistencia temporal de los propágulos (capacidad de formar banco de semillas o plántulas) y la respuesta a la luminosidad de las plántulas (tolerante a la sombra o intolerante). Los tipos de regeneración y el estado biológico en que pueden presentarse (semilla, plántula, juvenil o adul-

Tabla 1. Codificación utilizada para representar a los tipos de regeneración en los subsistemas semilla, plántula y comunidad. na: no aplica. $\mathrm{A}=$ dispersión animal, $\mathrm{V}=$ dispersión por el viento, $\mathrm{S}=$ forma banco de semillas, $\mathrm{P}=$ forma banco de plántulas, $\mathrm{T}=$ tolerante a la sombra, $\mathrm{I}=$ intolerante a la sombra.

\begin{tabular}{|c|c|c|c|c|}
\hline $\begin{array}{l}\text { Tipo de } \\
\text { regeneración }\end{array}$ & $\begin{array}{l}\text { Codificación empleada } \\
\text { en el subsistema } \\
\text { semilla }\end{array}$ & $\begin{array}{l}\text { Codificación empleada } \\
\text { en el subsistema } \\
\text { plántula }\end{array}$ & \multicolumn{2}{|c|}{$\begin{array}{l}\text { Codificación empleada } \\
\text { en el subsistema comunidad }\end{array}$} \\
\hline $\begin{array}{l}\text { APT: modo de dispersión } \\
\text { baro-endozoocoro; forma banco de } \\
\text { plántulas; y tolerante a la sombra }\end{array}$ & n.a. & 1 & $200-205$ & $206-299$ \\
\hline $\begin{array}{l}\text { ASPT: modo de dispersión endozoocoro; } \\
\text { forma banco de semillas y plántulas ; y } \\
\text { tolerante a la sombra }\end{array}$ & 10 & 100 & $300-305$ & $306-399$ \\
\hline $\begin{array}{l}\text { AST: modo de dispersión endozoocoro; } \\
\text { forma banco de semillas; y tolerante } \\
\text { a la sombra }\end{array}$ & 0.1 & 350 & $400-405$ & $406-465$ \\
\hline $\begin{array}{l}\text { ASPI: modo de dispersión endozoocoro; } \\
\text { forma banco de semillas y plántulas; e } \\
\text { intolerante a la sombra }\end{array}$ & 1 & 1,000 & $500-503$ & $504-535$ \\
\hline $\begin{array}{l}\text { ASI modo de dispersión endozoocoro; } \\
\text { forma banco de semillas; e intolerante } \\
\text { a la sombra }\end{array}$ & 0.01 & 75 & $600-605$ & $606-635$ \\
\hline $\begin{array}{l}\text { VPI: modo de dispersión anemócoro; } \\
\text { forma banco de plántulas; e intolerante } \\
\text { a la sombra }\end{array}$ & n.a. & 10 & $700-702$ & $703-735$ \\
\hline $\begin{array}{l}\text { VSPI: modo de dispersión anemócoro; } \\
\text { forma banco de semillas y plántulas; e } \\
\text { intolerante a la sombra }\end{array}$ & 0.001 & 10,000 & $900-903$ & $904-935$ \\
\hline $\begin{array}{l}\text { VSI: modo de dispersión anemócoro; } \\
\text { forma banco de semillas; e intolerante } \\
\text { a la sombra }\end{array}$ & 0.0001 & 125 & $800-802$ & $803-817$ \\
\hline
\end{tabular}


to) se identificaron con la codificación que se presenta en la Tabla 1.

En el subsistema comunidad, cada celda puede estar vacía u ocupada por algún tipo de regeneración en estado juvenil o adulto. Cada vez que transcurre un ciclo se agrega una unidad de edad a los individuos, los cuales mueren al alcanzar la senectud. Las celdas vacías pueden ser ocupadas por un individuo juvenil de un determinado tipo que se origina del banco de semillas o de plántulas. La longevidad asignada a los tipos de regeneración se definió considerando los patrones reportados para bosques tropicales, dado que el bosque mesófilo alberga especies de afinidad tropical y boreal. Las consideraciones de longevidad de los árboles que se tomaron fueron las siguientes: (1) las especies pioneras son de vida mucho más corta que las especies de comunidades maduras (Laurance et al., 2004) y (2) la longevidad de las especies varía entre 48 y 980 años, pero la mayoría de los árboles alcanza una longevidad menor de 400 años (Martínez-Ramos y Álvarez-Buylla, 1998). Se asumieron las siguientes longevidades: 50, 105, 195 y 300 años; la menor se asignó al tipo de regeneración con perfil colonizador (tipos con semillas dispersadas por el viento, que forman bancos de semillas y son intolerante a la sombra) y la más alta a los tipos con perfil competitivo (tipos cuya dispersión de las semillas es baro-endozoocoro, forman bancos de plántulas y son tolerantes a la sombra). A los tipos con perfil intermedio, la longevidad asignada consideró su mayor o menor similitud con los perfiles extremos; a los tipos más cercanos al perfil colonizador se les fijó una menor longevidad (Tabla

Tabla 2. Vecindarios definidos y procesos y tipos de regeneración con los que interactúa. $\mathrm{A}=$ dispersión animal, $\mathrm{V}=$ dispersión por el viento, $\mathrm{S}=$ forma banco de semillas, $\mathrm{P}=$ forma banco de plántulas, $\mathrm{T}=$ tolerante a la sombra, $\mathrm{I}=$ intolerante a la sombra.

Vecindad Procesos y tipos de regeneración

con los que interactúa

Vecindad base: presencia de al menos un árbol adulto en el vecindario

Vecindad 1: entre 0 y 3 celdas ocupadas, y entre 5 y 8 celdas vacías

Vecindad 2: 4 celdas vacías y 4 celdas ocupadas

Vecindad 3: entre 5 ó 6 celdas ocupadas y 2 ó 3 celdas vacías

Vecindad 4: entre 7 u 8 celdas ocupadas y 0 ó 1 celda vacía

Vecindad 5: entre 4 y 8 celdas ocupadas, y de 0 a 4 celdas vacías

Dispersión de las semillas de los tipos baro- endozoocoro: APT, ASPT, AST, ASPI y ASI.

Dispersión de las semillas de los tipos anemócoros: VPI, VSPI y VSI Germinación de las semillas de los tipos intolerantes a la sombra: ASPI, ASI, VPI, VSPI y VSI.

Dispersión de las semillas de los tipos anemócoros: VPI, VSPI y VSI.

Dispersión de las semillas de los tipos anemócoros: VPI, VSPI y VSI.

Dispersión de las semillas de los tipos anemócoros: VPI, VSPI y VSI.

Germinación de las semillas de los tipos tolerantes a la sombra: APT, ASPT y AST.
1). Para representar la edad de los tipos de regeneración, se determinó que cada ciclo de actualización del sistema corresponde a un periodo de tres años.

La dinámica de los bancos de semillas y de plántulas se simularon en los subsistemas correspondientes, en cada celda se representaron estos elementos sólo en términos de su presencia o ausencia y no de su abundancia. Asimismo, cada celda puede encontrarse vacía u ocupada con semillas o plántulas de uno o más tipos de regeneración (en el Apéndice 1 se presenta la lista de todos los estados en que pueden encontrarse las celdas de estos subsistemas). Se consideró que el banco de semillas es transitorio (Díaz-Perea et al., 2014), por lo que la simulación mantuvo viables a las semillas de la misma cohorte sólo durante un ciclo y al segundo ciclo fueron eliminadas. Las semillas y plántulas de cada uno de los tipos de regeneración se etiquetaron (Tabla 1), para identificar y rastrearlas en los subsistemas correspondientes.

Reglas de transición. Los procesos biológicos simulados en el AC fueron: la dispersión de las semillas, germinación, persistencia temporal de los propágulos (banco de semillas y de plántulas), el cambio de estado de juvenil a adulto, el envejecimiento y muerte natural de los árboles (Figura 1). Al finalizar cada ciclo los subsistemas se actualizan de la siguiente forma: el banco de semillas almacena las nuevas simientes que se produjeron en ese periodo (las semillas del periodo previo que no germinaron se eliminaron). En el banco de plántulas se conservan las plántulas que no prosperaron a individuos juveniles y se adicionan las plántulas que se formaron en ese periodo y en el subsistema comunidad se suma una unidad de tiempo (corresponde a tres años) a la edad de los individuos. Si alguno rebasa la edad máxima muere y la celda ocupada por el individuo sólo se vacía, este suceso no afecta a la vecindad. Las celdas que al inicio del ciclo estaban vacías pueden continuar desocupadas u ocuparse con un juvenil de cualquier tipo de regeneración, lo cual dependerá de los bancos de semillas y plántulas presentes en la celda y las condiciones de hábitat existentes (vecindad).

Condiciones de hábitat. Considerando la densidad de árboles adultos alrededor de cada celda se definieron cinco clases de vecindad, las cuales representan las condiciones de hábitat y son determinantes en los procesos de dispersión, germinación de las semillas y establecimiento de los juveniles. En los subsistemas banco de semillas y banco de plántulas, el tipo de vecindad es clave para definir el estado discreto que tomarán las celdas en el ciclo subsecuente. En el Tabla 2 se relacionan las condiciones de hábitat (vecindades) y los procesos y tipos de regeneración con los cuales interactúan.

Reproducción y dispersión de las semillas. El modelo considera que sólo los individuos adultos se reproducen. El pri- 


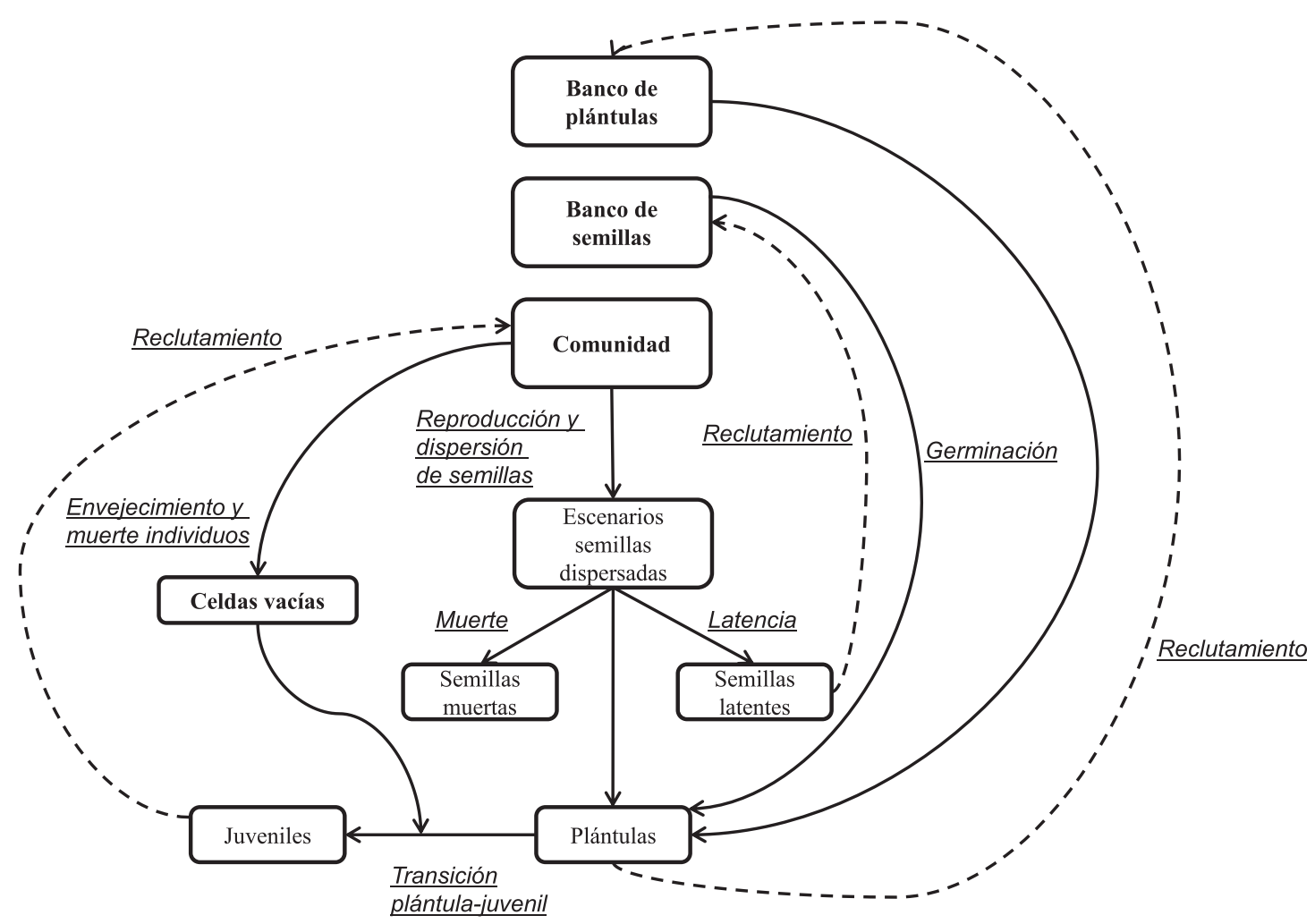

Figura 1. Diagrama de los procesos de regeneración del bosque mesófilo simulados en el AC y subsistemas del bosque. Las flechas continuas indican el flujo de los procesos de regeneración, las flechas discontinuas indican el flujo para la actualización de los subsistemas del modelo.

mer paso en la modelación es identificar a los árboles adultos de la comunidad para aplicar las funciones de dispersión de semillas. Este es un proceso complejo que depende de un gran número de factores. La distancia a la que pueden diseminarse las semillas con modo de dispersión anémocora depende de la velocidad y la turbulencia del viento, la altura de los individuos madre y el tamaño y forma de las semillas (Horn et al., 2001). Por otra parte, la dirección y distancia máxima de la dispersión de las especies endozoocoras depende del comportamiento de los animales (Hughes et al., 1994). No obstante, la gran mayoría de las semillas tienden a dispersarse en las cercanías de la planta madre (Nathan, 2006) y en muchas especies la mayoría de las semillas se dispersan a una distancia de entre 1 y 2 diámetros de la copa del dosel de la planta madre (Hughes et al., 1994). Bajo estas consideraciones, en el modelo se asumió que las semillas se dispersan en forma homogénea alrededor de la planta madre y se definió una distancia de dispersión de dos celdas alrededor de dicha planta.

La diseminación de las semillas con modo de dispersión baro-endozoocora ocurre en todas las celdas de la plantilla en las que exista un árbol o en las celdas vacías en las que al menos exista un árbol en su vecindad. En los tipos con modo de dispersión anemócoro, las semillas se diseminan en todas las celdas de la plantilla excepto bajo la copa del árbol madre; asimismo, la probabilidad de que las semillas arriben al suelo dependerá de la cobertura del dosel (a mayor cobertura, menor es la probabilidad de que una semilla llegue al suelo), de acuerdo con las relaciones establecidas en la Tabla 3.

Germinación. Para simular la germinación de las semillas los tipos de regeneración se agruparon en tolerantes e intolerantes a la sombra. La germinación en los primeros ocurre en celdas con una vecindad de 4 a 8 celdas ocupadas por un árbol adulto y en los tipos intolerantes a la sombra la germinación sucede en celdas con vecindad de 5 a 8 celdas vacías. Se asumieron estos dos tipos contrastantes de vecindario, suponiendo que cuando una celda central está rodeada por

Tabla 3. Probabilidad de las semillas anemócoras de arribar al suelo en función de la saturación (densidad) alrededor de la celda.

\begin{tabular}{cc}
\hline Condición de hábitat & $\begin{array}{c}\text { Probabilidad de } \\
\text { la semilla de } \\
\text { arribar al suelo }\end{array}$ \\
\hline
\end{tabular}

Vecindad 1: entre 0 y 3 celdas ocupadas, $y$ 1 entre 5 y 8 celdas vacías

Vecindad 2: 4 celdas vacías y 4 celdas ocupadas

Vecindad 3: entre 5 ó 6 celdas ocupadas y 2 ó 3 celdas vacías

Vecindad 4: entre 7 u 8 celdas ocupadas y 0 ó 1 celda vacía 
cuatro o más individuos se establecen condiciones de sombra en dicha celda; mientras que una celda que esté rodeada sólo por un máximo de tres individuos representa un sitio que recibe una cantidad considerable de luz.

Por otra parte, para todos los tipos de regeneración se aplicó una probabilidad de germinación de 0.8 y para los tipos de regeneración con semillas recalcitrantes (acrónimo APT -dispersión Animal_forma banco de Plántulas_Tolerante a la sombra- y VPI -dispersión Viento_forma banco de Plántulas_Intolerante a la sombra-) se adoptó la regla de que las semillas que no germinan mueren antes de iniciar el siguiente ciclo.

Transición de plántulas a juveniles. La transición de plántula a juvenil sólo ocurre en las celdas vacías del subsistema comunidad. Las plántulas se mantienen suprimidas en las celdas ocupadas pero cuando muere un árbol puede sobrevenir el establecimiento de un individuo juvenil bajo las siguientes reglas: a) si en el banco de plántulas concurren varios tipos de regeneración el tipo que se establecerá dependerá de las condiciones de hábitat; los tipos intolerantes a la sombra prosperarán en las celdas con vecindad de 5 a 8 celdas vacías y los tolerantes a la sombra en las celdas con vecindad de 4 a 8 celdas ocupadas. Si coexisten varios tipos tolerantes o intolerantes a la sombra, el tipo específico que se establezca se determina de manera aleatoria.

Si en la celda no existen plántulas pero si un banco de semillas, podrá ocurrir la germinación y establecimiento de un juvenil, dependiendo de las condiciones de hábitat imperantes: en celdas con una vecindad de 5 a 8 celdas vacías se favorece el establecimiento de los tipos intolerantes a la sombra; en celdas con una vecindad de 4 a 8 celdas ocupadas se favorece el establecimiento de tipos tolerantes a la sombra.

Implementación. El AC se implementó en el lenguaje $\mathrm{R}(\mathrm{R}$ Core Team, 2015) utilizando la biblioteca de aplicación SIMECOL (Petzoldt y Rinke, 2007). Esta biblioteca ofrece una arquitectura generalizada para desarrollar modelos ecológicos. SIMECOL tiene la ventaja de producir una codificación de fácil lectura, lo que significa simplicidad para modificar las plantillas de los simuladores. Por ello, los modelos resultan altamente adaptables para satisfacer los requerimientos de los usuarios. Se tomó como prototipo stoch_ca_simple para construir el simulador de la regeneración del bosque mesófilo, con el diseño estructural y las reglas de transición referidas. La operación de SIMECOL requiere de la instalación previa en $\mathrm{R}$ de las aplicaciones deSolve (Soetaert et al., 2010) y lattice (Sarkar, 2008).

Configuración inicial de la comunidad del bosque mesófilo. Para la simulación de la dinámica base se preparó una comunidad inicial de 2,500 árboles (plantilla de 50 filas por 50 columnas), extrapolando la estructura de la comunidad del bosque mesófilo de la zona de estudio estimada a partir del muestreo de la vegetación (Díaz-Perea et al., 2014). Los rasgos estructurales considerados fueron: la densidad promedio de los árboles en la comunidad, la proporción en la que se encuentran representados los tipos de regeneración y la proporción de las tallas (DAP) de los individuos en las poblaciones de cada tipo de regeneración. Finalmente, los individuos se distribuyeron en forma aleatoria en la plantilla base y así se generó la comunidad inicial.

Arquitectura del simulador. Para facilitar el uso del simulador (disponible con los autores), éste se estructuró en seis módulos; en cada uno se proporciona una descripción de las etapas de la modelación y de los comandos y opciones que se aplicaron con la finalidad de transparentar la codificación del modelo.

Construcción matriz comunidad inicio. En este archivo se desarrollaron las funciones estruc.comunidad que permite preparar la comunidad inicial con base en los registros del muestreo de la vegetación y genera.parametros con la cual se generan las plantillas para simular los diferentes modos de dispersión de las semillas y la lista de valores para parametrizar a las diferentes fases del ciclo de vida de los tipos de regeneración (semilla, plántula, juvenil, adulto y senescente) y la lista de probabilidades empleadas en la modelación.

Instrucciones automata celular. Este archivo contiene las reglas que definen las condiciones de hábitat y de transición del AC. Al finalizar de aplicar todas las reglas se actualiza el estado de los subsistemas comunidad y bancos de semillas y de plántulas.

Simulador reg BMM.- Este archivo realiza la simulación para lo cual llama a los archivos que contiene las funciones estruc.comunidad y genera.parametros y las instrucciones de simulación. La simulación se desarrolla con el comando gridModel, fijando el nombre de la matriz para iniciar la simulación, el método para la simulación ("iteration") y el número de iteraciones que se realizarán. Se obtiene un archivo que contiene los escenarios generados (uno por cada iteración).

Análisis simulador.- En este archivo se realiza el análisis de los escenarios que se obtienen con la simulación. En primer término se importan los archivos utilizados en el análisis de simulación, se ejecuta la función de los parámetros utilizados en la simulación y finalmente se importa el archivo con los resultados de la simulación. Se preparó una rutina para analizar los escenarios en los subsistemas comunidad, banco de semillas y banco de plántulas. El análisis consiste en comparar los escenarios en función del número de celdas ocupadas por los diferentes estados. Se generan tablas, gráficas de barras y rejillas con las celdas teñidas de diferente color representando a los diferentes estados de los subsistemas. 
Disturbio.- este archivo permite realizar tratamientos de disturbios de diferente intensidad al sistema. El disturbio consiste en eliminar árboles y/o semillas y/o plántulas del sistema. La intensidad del disturbio depende de la superficie (número de celdas) y los componentes afectados. Los tratamientos pueden aplicarse a cualquiera de los escenarios que se obtienen con la simulación a partir de la comunidad original.

Simulador reg BMM_Dist.- Este archivo opera igual que Simulador reg BMM, la diferencia es que ejecuta la simulación a un sistema al que se le aplicó un tratamiento de disturbio, por lo que el archivo del sistema inicial se exporta del archivo Disturbio.

Simulaciones. Se simuló la dinámica del bosque ejecutando el AC durante 100 iteraciones y se analizaron los escenarios de los subsistemas comunidad, banco de semillas y banco de plántulas que resultaron cada diez iteraciones. Los tratamientos simulados fueron los siguientes:

Dinámica Base.- Sin disturbios, la mortalidad natural de los árboles fue el único factor que los elimina de la comunidad. Disturbio de severidad ligera.- para representar un disturbio de severidad ligera, se tomó el escenario 60 de la simulación base y se eliminaron los árboles en 289 celdas (cuadrícula de $17 \times 17$ celdas) en la parte central de la plantilla, que representa el $11.5 \%$ de la comunidad. El análisis de los escenarios se realizó en una sección de la plantilla que incluye el área perturbada y un buffer de un ancho de tres celdas alrededor de esta zona. Esta sección de la plantilla es la que se reporta en los resultados.

Disturbio de gran severidad.- para representar un disturbio de gran severidad se tomó el escenario 60 de la simulación base y eliminaron los árboles y los bancos de semillas y plántulas en 289 celdas que representa el $11.5 \%$ de la plantilla. El análisis de los escenarios se realizó en la sección que incluye el área perturbada de la plantilla y un buffer de un ancho de tres celdas alrededor de esta zona. Esta sección de la plantilla es la que se reporta en los resultados.

\section{Resultados}

Dinámica base. En la comunidad de árboles se detectaron los siguientes cambios estructurales (Figura 2): la disminución gradual de la población del tipo APT (dispersión por Animales_forma banco Plántulas_Tolerante a la sombra) y

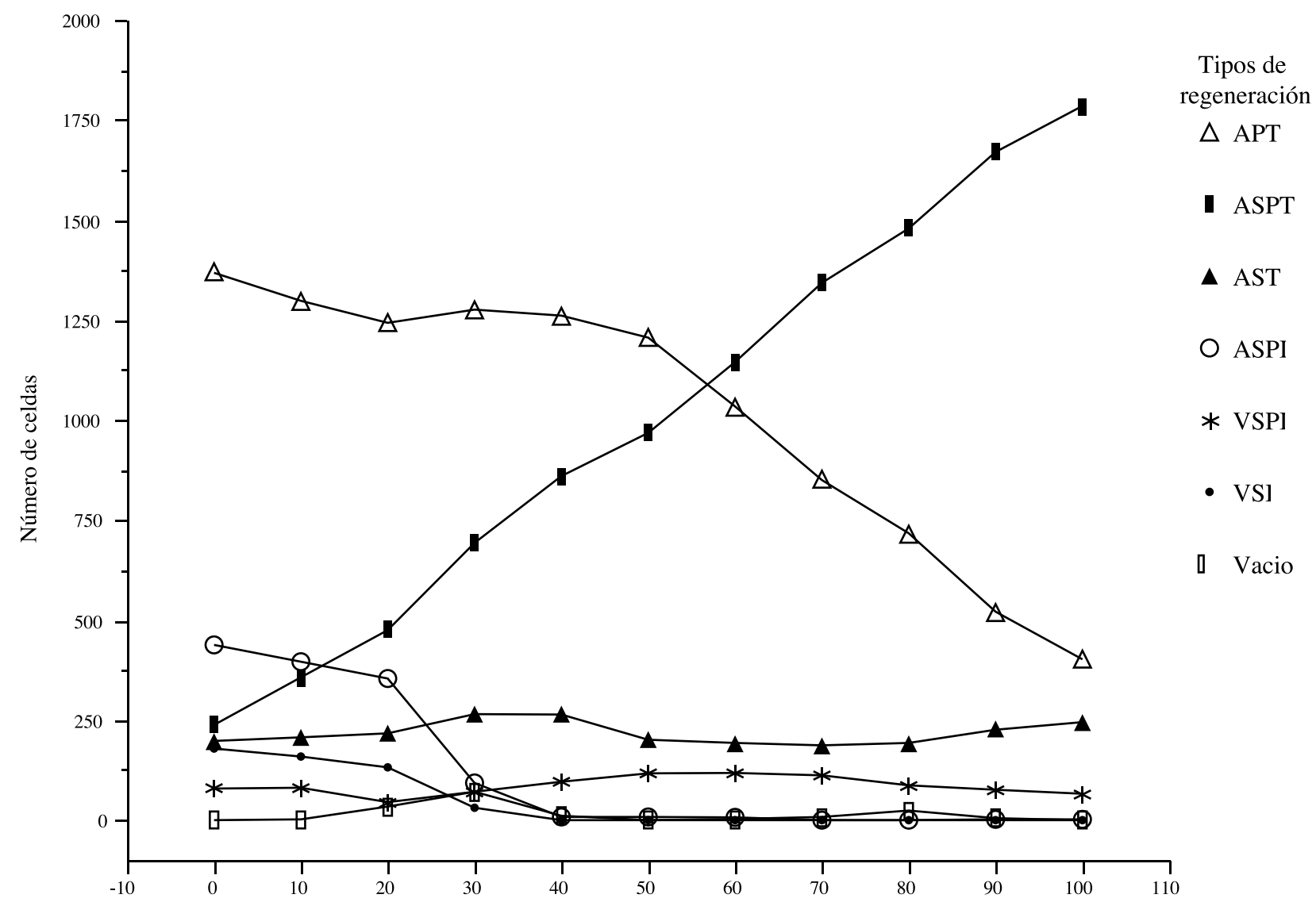

Tiempo

Figura 2. Escenarios de la dinámica base en la comunidad de árboles del bosque mesófilo. 

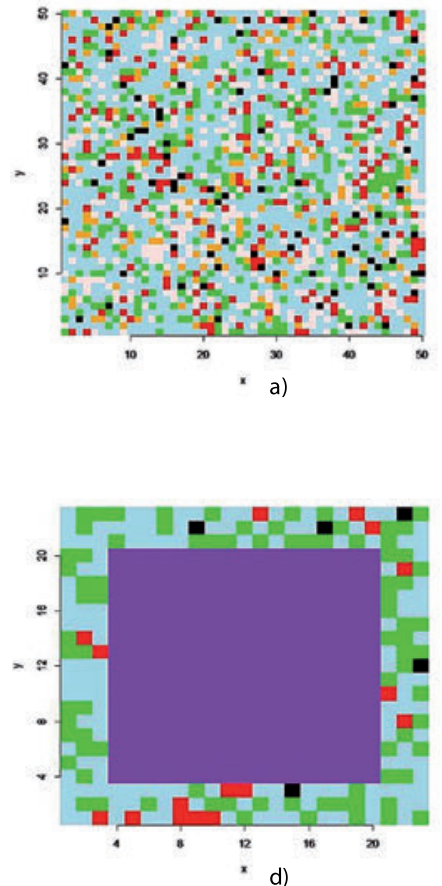
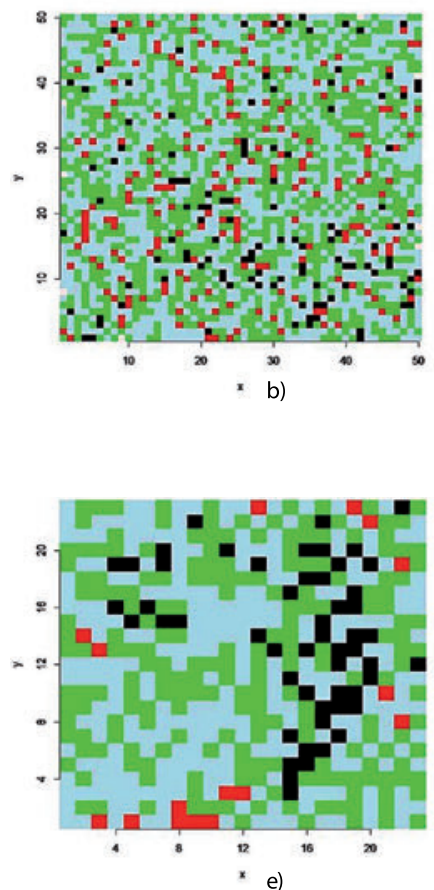
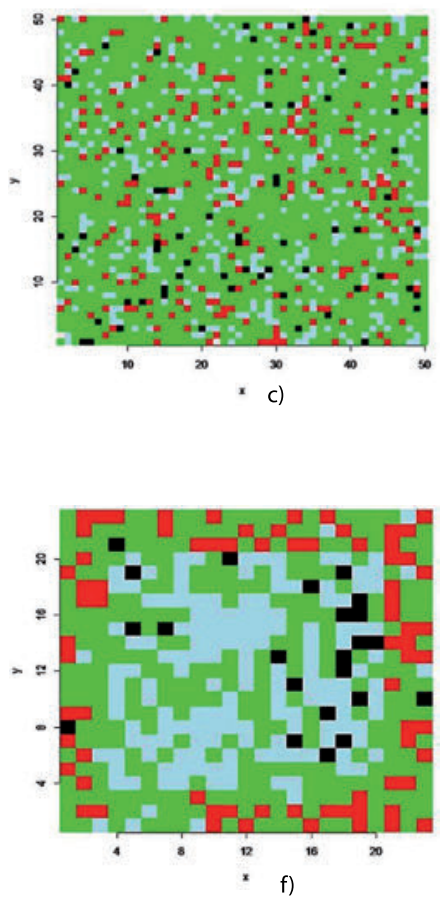

Figura 3. Escenarios de la dinámica de la comunidad de árboles del bosque mesófilo: a-c escenarios de la dinámica base, sin disturbio (a = iteración 10, b = iteración 50 y c= iteración 100); y d-f escenarios posterior a un disturbio de severidad ligera $(\mathrm{d}=$ inicio, e = iteración 10 y f = iteración final). APT = Azul; ASPT = Verde; AST = Rojo; ASPI = Rosa; VSI= Naranja; VSPI = Negro; celda vacía = morado.

el incremento del tipo ASPT (dispersión por Animales_forma bancos de Semillas y Plántulas_Tolerante a la sombra); la eliminación en la comunidad del tipo VSI (dispersión por Viento_forma banco de Semillas_Intolerante a la sombra) y la casi desaparición del tipo ASPI (dispersión por Animales_forma bancos de Semillas y Plántulas_Intolerante a la sombra). Los tipos AST (dispersión por Animales_forma bancos de Semillas_Tolerante a la sombra), y VSPI (dispersión por Viento_forma bancos de Semillas y Plántulas_Intolerante a la sombra) no modifican su población en forma significativa. Al agrupar a los tipos de regeneración por su respuesta a la luz, se apreció que se acrecienta la dominancia de los tipos tolerantes a la sombra (perfil competidor), pues al inicio de la dinámica los árboles tolerantes a la sombra representaban el $72 \%$ de la comunidad y al fin del periodo simulado constituían el $97 \%$. Es notable que al final de la simulación el número de tipos de regeneración fue menor, es decir el bosque pierde diversidad funcional (Figura 3).

En el banco de semillas, el tipo VSI desaparece de este subsistema y el tipo ASPI reduce drásticamente su presencia. Los tipos ASPT, AST y VSPI mantienen su distribución sin cambios significativos. El número de celdas vacía se incrementa de manera importante y se estabiliza a partir de la iteración cuatro (Figura 4).

En el banco de plántulas se presenta un incremento en la presencia del tipo de regeneración VSPI y se mantiene sin cambios importantes la distribución de los tipos APT, ASPT y ASPI (Figura 5). En este banco son pocas las celdas vacías, a diferencia de lo que se observó en el banco de semillas. Es de esperar que la gran reserva de plántulas de los tipos APT y ASPT se traduzca en una gran abundancia en la comunidad de árboles, lo cual no ocurre en la población de árboles del tipo APT que por el contrario manifiesta una brusca disminución de la población conforme transcurre el tiempo. Esta inconsistencia sugiere que existen limitaciones en el establecimiento de los juveniles de este tipo de regeneración.

Dinámica de la comunidad posterior a un disturbio de severidad ligera. La comunidad de árboles se recuperó inmediatamente a partir de los bancos de semillas y plántulas (Figuras 3, 6). En la primera iteración el claro inducido se repobló con individuos de los tipos ASPT, APT y VSPI. La población ASPT creció de manera importante y al final del periodo simulado alcanzó una gran abundancia (en el área perturbada el $52 \%$ de los árboles son de este tipo); sin embargo, fue menor que la abundancia que se presentó al final de la simulación base (71 \%).

Por su parte, la población del tipo APT creció en las primeras iteraciones y después disminuyó, al finalizar la simulación la población fue de tamaño similar a la del inicio (representa alrededor del $30 \%$ de los árboles de la comunidad). La dinámica de este tipo contrasta con lo observado en la simulación base en la cual la población APT se redujo en forma significativa (al finalizar el $16 \%$ de los árboles de la comunidad eran de este tipo). Bajo este tratamiento no desapareció ningún tipo de regeneración durante la evolución de la comunidad; pero al inicio de la simulación no estaban reprresentados los tipos ASPI y VSI.

La dinámica del banco de semillas con este tratamiento 


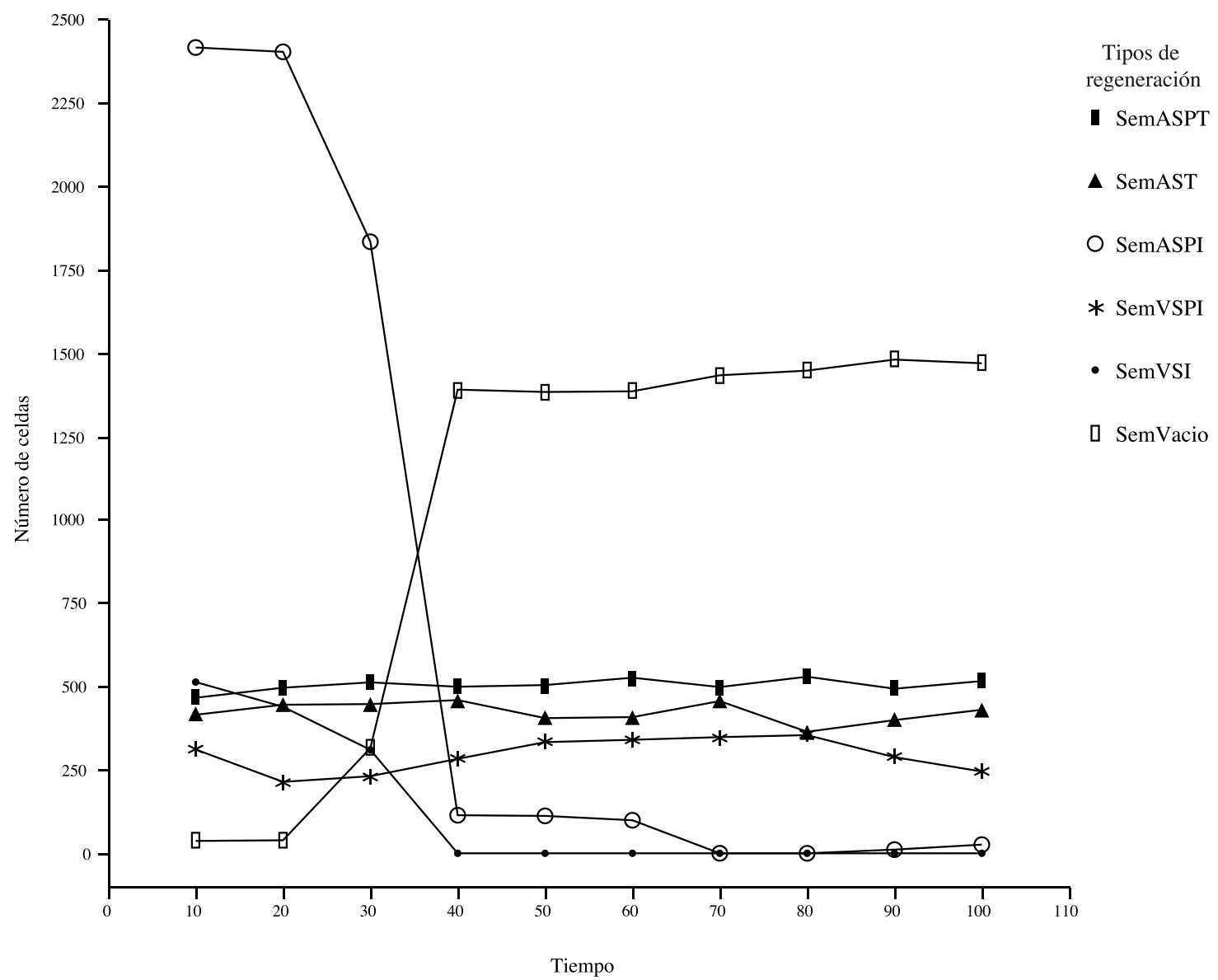

Figura 4. Escenarios de la dinámica base del banco de semillas en el bosque mesófilo.

es muy similar a la observada en la simulación base (Tabla 4). La distribución en la plantilla de los tipos ASPT, AST y VSPI se mantienen sin cambios significativos; asimismo, la mayor parte de las celdas en la plantilla no tienen semillas (entre el 59 y $66 \%$ ).

En el banco de plántulas la distribución de todos los tipos de regeneración se mantiene sin cambios importantes a lo largo de la simulación (Tabla 5). A semejanza de lo observado en la dinámica base, los tipos APT y ASPT se distribuyen en prácticamente toda la plantilla y aumenta la presencia del tipo VSPI (la ocupación de celdas crece del 50 al $73 \%$ ); y las celdas que no presentan plántulas son escasas.

Dinámica de la comunidad posterior a un disturbio de gran severidad. Con el disturbio de esta intensidad, la recuperación de la comunidad de árboles es más lenta (el claro se ve repoblado después de la iteración 20) que en los disturbios de severidad baja y se inicia en los bordes entre el claro y la comunidad arbolada, como cabría esperar en condiciones reales. Asimismo, la colonización del claro ocurrió sólo con individuos de los tipos ASPT y VSPI (Figuras 7, 8).

Bajo estas condiciones de disturbio, al inicio de la simulación el tipo de regeneración VSPI tiene una baja abundancia en la comunidad y su población crece rápidamente en el área perturbada. Llegó a representar el $31 \%$ de la comunidad para luego declinar, al final de la simulación la población VSPI representó el $16 \%$ de la comunidad. Este patrón difiere del observado en la dinámica que se genera con las otras dos simulaciones, en éstas la población de este tipo se mantiene por debajo de $10 \%$ de la comunidad todo

Tabla 4. Escenarios de la dinámica del banco de semillas posterior a un disturbio de severidad ligera, se reporta el número de celdas que son ocupadas por semillas de cada tipo de regeneración.

\begin{tabular}{lcccccc}
\hline \multicolumn{6}{c}{ Escenarios en banco de semillas } \\
\multicolumn{7}{c}{ (número de celdas ocupadas por tipo de regeneración) } \\
& SemASPT & SemAST & SemASPI & SemVSPI & SemVSI & SemVacio \\
\hline $\mathbf{0}$ & 108 & 86 & 0 & 50 & 0 & 317 \\
$\mathbf{1 0}$ & 114 & 46 & 0 & 67 & 0 & 338 \\
$\mathbf{2 0}$ & 88 & 47 & 0 & 74 & 0 & 351 \\
$\mathbf{3 0}$ & 114 & 40 & 0 & 74 & 0 & 320 \\
$\mathbf{4 0}$ & 108 & 50 & 0 & 68 & 0 & 328 \\
$\mathbf{5 0}$ & 96 & 48 & 0 & 68 & 0 & 345 \\
$\mathbf{6 0}$ & 93 & 51 & 0 & 67 & 0 & 339 \\
$\mathbf{7 0}$ & 116 & 39 & 0 & 61 & 0 & 337 \\
$\mathbf{8 0}$ & 102 & 46 & 0 & 54 & 0 & 348 \\
$\mathbf{9 0}$ & 117 & 69 & 0 & 61 & 0 & 314 \\
$\mathbf{1 0 0}$ & 100 & 61 & 0 & 53 & 0 & 341 \\
\hline
\end{tabular}




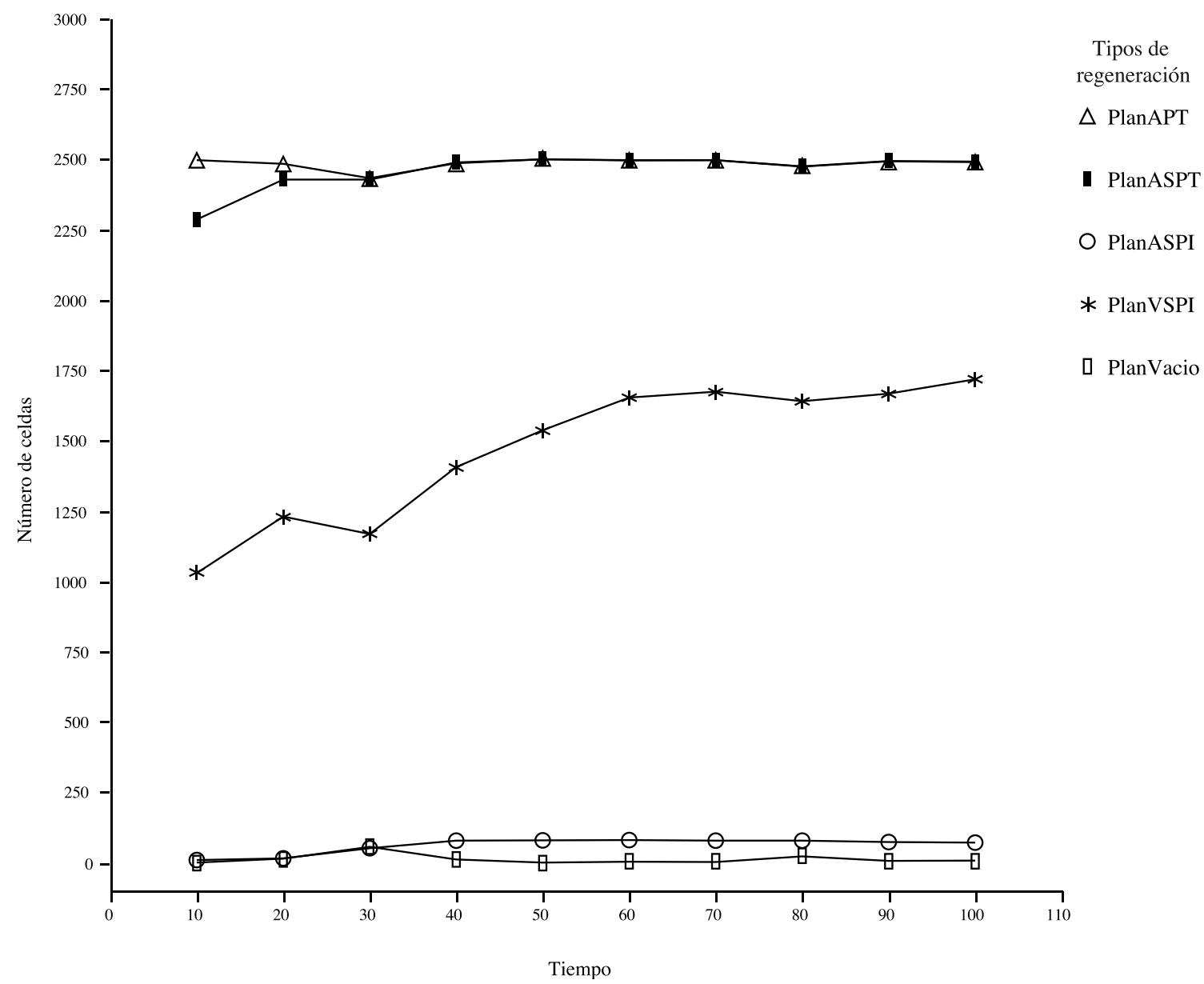

Figura 5. Escenarios de la dinámica base del banco de plántulas en el bosque mesófilo.

el tiempo. Por otra parte, la abundancia del tipo APT en esta dinámica es menor que en las otras dos simulaciones realizadas. En el último escenario su abundancia es del orden de $8.5 \%$ mientras que en las otras dinámicas es de $16 \%$

Tabla 5. Escenarios de la dinámica del banco de plántulas posterior a un disturbio de severidad ligera, se reporta el número de celdas que son ocupadas por plántulas de cada tipo de regeneración.

\begin{tabular}{|c|c|c|c|c|c|}
\hline \multicolumn{6}{|c|}{$\begin{array}{c}\text { Escenarios de banco de plántulas } \\
\text { (número de celdas ocupadas por tipo de regeneración) }\end{array}$} \\
\hline & PlanAPT & PlanASPT & PlanASPI & PlanVSPI & PlanVacío \\
\hline $\mathbf{0}$ & 529 & 529 & 2 & 264 & 0 \\
\hline 10 & 528 & 529 & 2 & 212 & 0 \\
\hline 20 & 529 & 529 & 2 & 340 & 0 \\
\hline 30 & 527 & 527 & 2 & 365 & 2 \\
\hline 40 & 529 & 529 & 1 & 368 & 0 \\
\hline 50 & 528 & 528 & 1 & 383 & 1 \\
\hline 60 & 529 & 529 & 1 & 340 & 0 \\
\hline 70 & 529 & 529 & 1 & 384 & 0 \\
\hline 80 & 529 & 529 & 1 & 387 & 0 \\
\hline 90 & 529 & 529 & 1 & 385 & 0 \\
\hline 100 & 529 & 529 & 1 & 387 & 0 \\
\hline
\end{tabular}

(sin disturbio) y $30 \%$ (disturbio de severidad ligera). Otras particularidades de esta dinámica es que los tipos tolerantes a la sombra (APT, ASPT y AST) manifiestan una menor abundancia que la observada en las otras simulaciones. Asimismo, destaca "la huella del disturbio" que se mantiene durante todo el periodo de simulación, se evidencia por la

Tabla 6. Escenarios de la dinámica del banco de semillas posterior a un disturbio de gran severidad, se reporta el número de celdas que son ocupads por semillas de cada tipo de regeneración.

\begin{tabular}{ccccccc}
\hline & SemASPT & SemAST & SemASPI & SemVSPI & SemVSI & SemVacio \\
\hline 0 & 43 & 34 & 0 & 21 & 0 & 445 \\
10 & 118 & 58 & 0 & 44 & 0 & 350 \\
20 & 87 & 47 & 0 & 80 & 0 & 347 \\
30 & 102 & 40 & 0 & 103 & 0 & 305 \\
40 & 97 & 50 & 0 & 63 & 0 & 341 \\
50 & 89 & 48 & 0 & 75 & 0 & 345 \\
60 & 90 & 51 & 0 & 111 & 0 & 313 \\
70 & 138 & 40 & 0 & 102 & 0 & 284 \\
80 & 113 & 46 & 0 & 70 & 0 & 325 \\
90 & 117 & 69 & 0 & 76 & 0 & 300 \\
100 & 100 & 62 & 0 & 72 & 0 & 325 \\
\hline
\end{tabular}




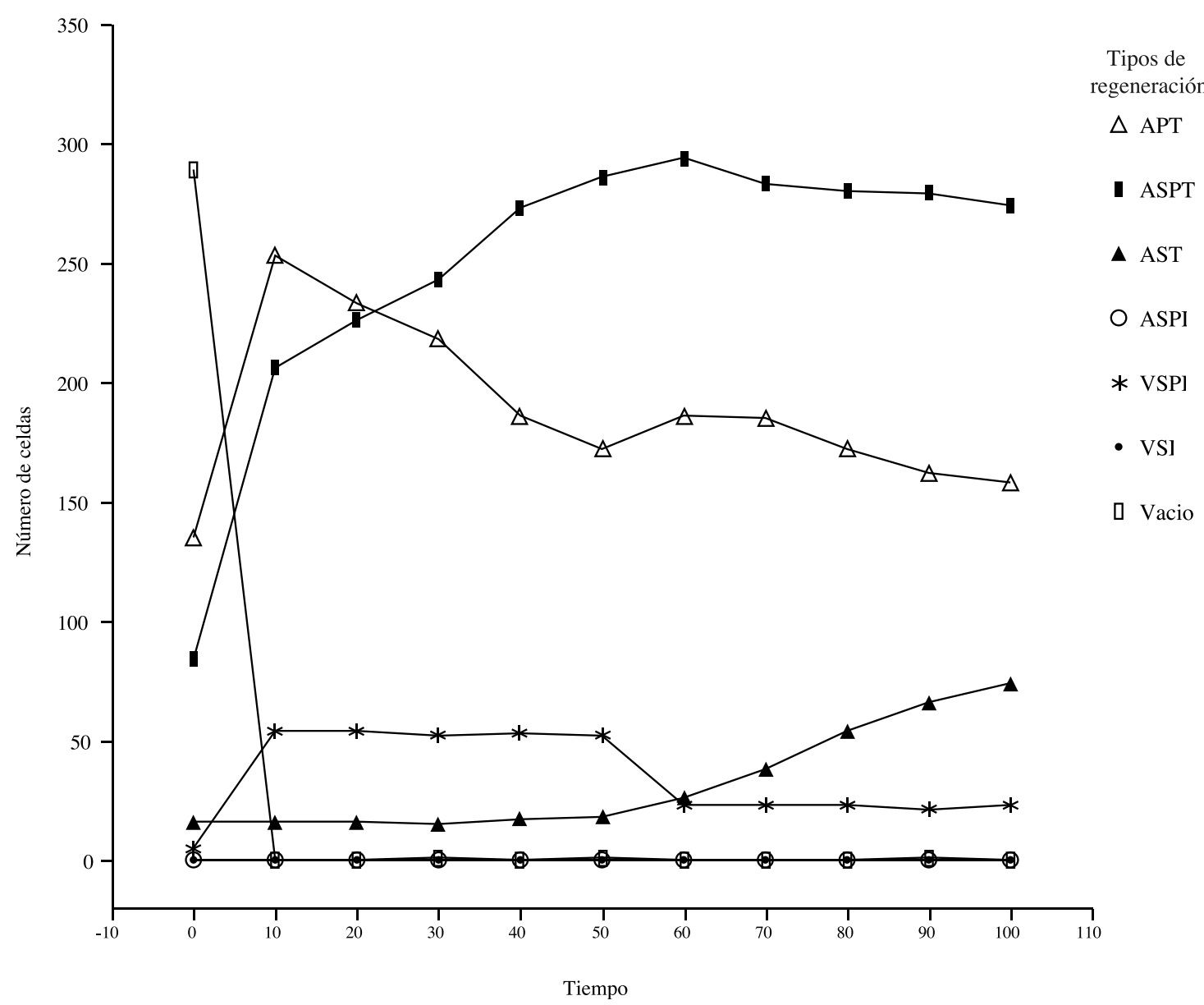

Figura 6. Escenarios de la dinámica en la comunidad de árboles del bosque mesófilo posterior a un disturbio de severidad ligera.

distribución del tipo de regeneración VSPI (que tiene un perfil colonizador) y como se esperaba colonizó el claro (ver secuencia de escenarios en la Figura 8).

El banco de semillas presenta la siguiente dinámica. $\mathrm{Al}$ iniciar la simulación el área perturbada no tiene semillas, éstas sólo se presentan en la zona de amortiguamiento (tres

Tabla 7. Escenarios de la dinámica del banco de plántulas posterior a un disturbio de gran severidad, se reporta el número de celdas que son ocupadas por plántulas de cada tipo de regeneración.

\begin{tabular}{cccccc}
\hline & PlanAPT & PlanASPT & PlanASPI & PlanVSPI & PlanVacío \\
\hline 0 & 240 & 240 & 2 & 122 & 289 \\
10 & 326 & 331 & 2 & 196 & 182 \\
20 & 368 & 418 & 2 & 277 & 82 \\
30 & 373 & 471 & 2 & 396 & 2 \\
40 & 375 & 486 & 1 & 410 & 0 \\
50 & 374 & 485 & 1 & 432 & 1 \\
60 & 367 & 466 & 1 & 412 & 25 \\
70 & 425 & 503 & 1 & 436 & 0 \\
80 & 466 & 525 & 1 & 432 & 0 \\
90 & 475 & 529 & 1 & 435 & 0 \\
100 & 475 & 529 & 1 & 437 & 0 \\
\hline
\end{tabular}

celdas alrededor del área perturbada). A partir de la iteración 40 el patrón de distribución de las semillas en la plantilla es muy similar a la observada en las otras dos simulaciones, lo que sugiere que este componente del sistema ya se recuperó del impacto que le provocó el disturbio (Tabla 6).

La dinámica del banco de plántulas mostró que hasta la iteración 40 las plántulas se distribuyeron en toda la zona perturbada (Tabla 7). Asimismo, a lo largo de la simulación se observa una mayor abundancia del tipo VSPI en esta zona con respecto a lo observado en el banco de plántulas derivado de un disturbio de baja severidad. Este patrón es razonable considerando que el tipo VSPI tiene un perfil colonizador, por lo cual es de esperar que sus propágulos persistan en sitios afectados por disturbios de gran severidad.

\section{Discusión}

Los escenarios obtenidos con la ejecución del AC aplicando diferentes tratamientos (disturbio y no disturbio) al bosque mesófilo, indican que el modelo instrumentado representa razonablemente la dinámica de este bosque y su respuesta a disturbios de diferente severidad.

Un componente novedoso del modelo desarrollado fue 


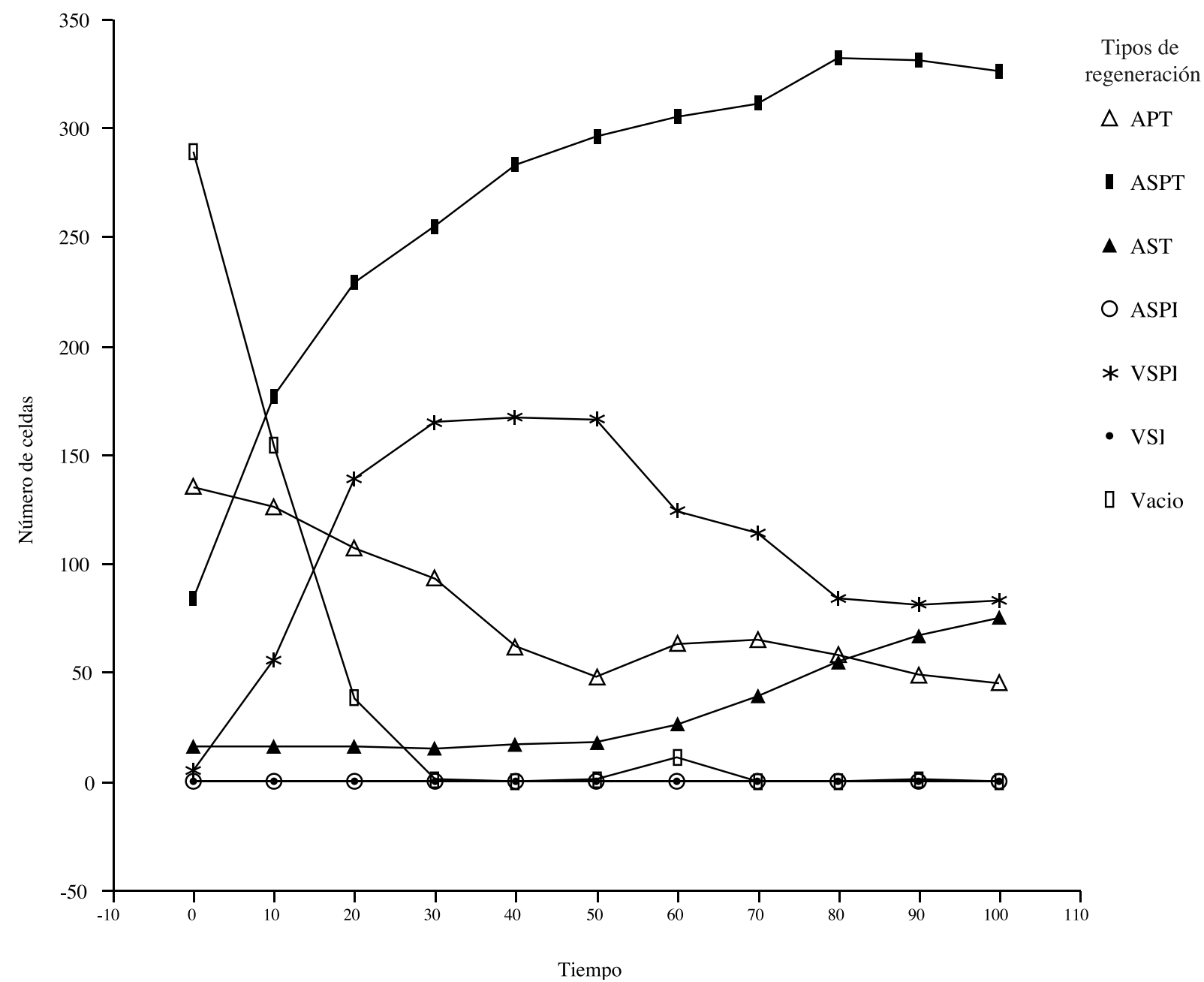

Figura 7. Escenarios de la dinámica del la comuidad de árboles del bosque mesófilo posterior a un disturbio de gran severidad.

integrar y manejar de manera independiente a los subsistemas bancos de semillas y de plántulas. Con la integración de estos subsistemas se superó una debilidad de muchos modelos desarrollados para simular la dinámica de los bosques, que no consideran la disponibilidad de los propágulos en el sistema (Busing y Mailly, 2004). El banco de semillas es importante para el reclutamiento de nuevos individuos arbóreos, por lo que es un factor clave para la regeneración de las comunidades de plantas después de un disturbio natural o antropogénico (Alvarez-Aquino et al., 2005). Por su parte, el banco de plántulas es importante para la regeneración de especies arbóreas en el bosque mesófilo (Sosa y Puig, 1987, Saldaña-Acosta et al., 2008).

El modelo también consideró la heterogeneidad ambiental, definida con base en la densidad de árboles en la vecindad de cada celda, lo cual representó una mejora respecto de algunos otros modelos (Price et al., 2001). Con la incorporación al modelo de estos componentes se tiende hacia una simulación más completa del complejo proceso de regeneración del bosque y aun así se mantiene una estructura programática manejable e inteligible para el usuario.
La dinámica base reveló que ante la falta de disturbios, la comunidad evoluciona adquiriendo las siguientes características estructurales: (1) progresivamente crece la abundancia de los tipos con un perfil competidor (APT y ASPT) mientras que los tipos con perfil colonizador (ASPI y VSPI) reducen su abundancia y el tipo con el perfil más pionero (VSI) es excluido y (2) se reduce la diversidad funcional (el número de tipos de regeneración). Estos resultados son consistentes con la hipótesis del disturbio medio (Connell, 1978; Shea et al., 2004; Roxburgh et al., 2004)), la cual establece que conforme se alarga el lapso entre la ocurrencia de disturbios la diversidad de las comunidades se reduce, ya sea porque las especies competidoras excluyen a las otras especies o porque persisten sólo las especies resistentes al estrés ambiental o a los enemigos externos cuando las especies de la comunidad son igualmente competidoras.

La dinámica que sigue la comunidad de árboles después de disturbio de severidad ligera reveló que ésta se recuperó rápidamente (el claro se cerró en la primera iteración) y el tipo de regeneración ASPT tiene una mayor contribución a la colonización del claro. En los bancos de semillas y de 

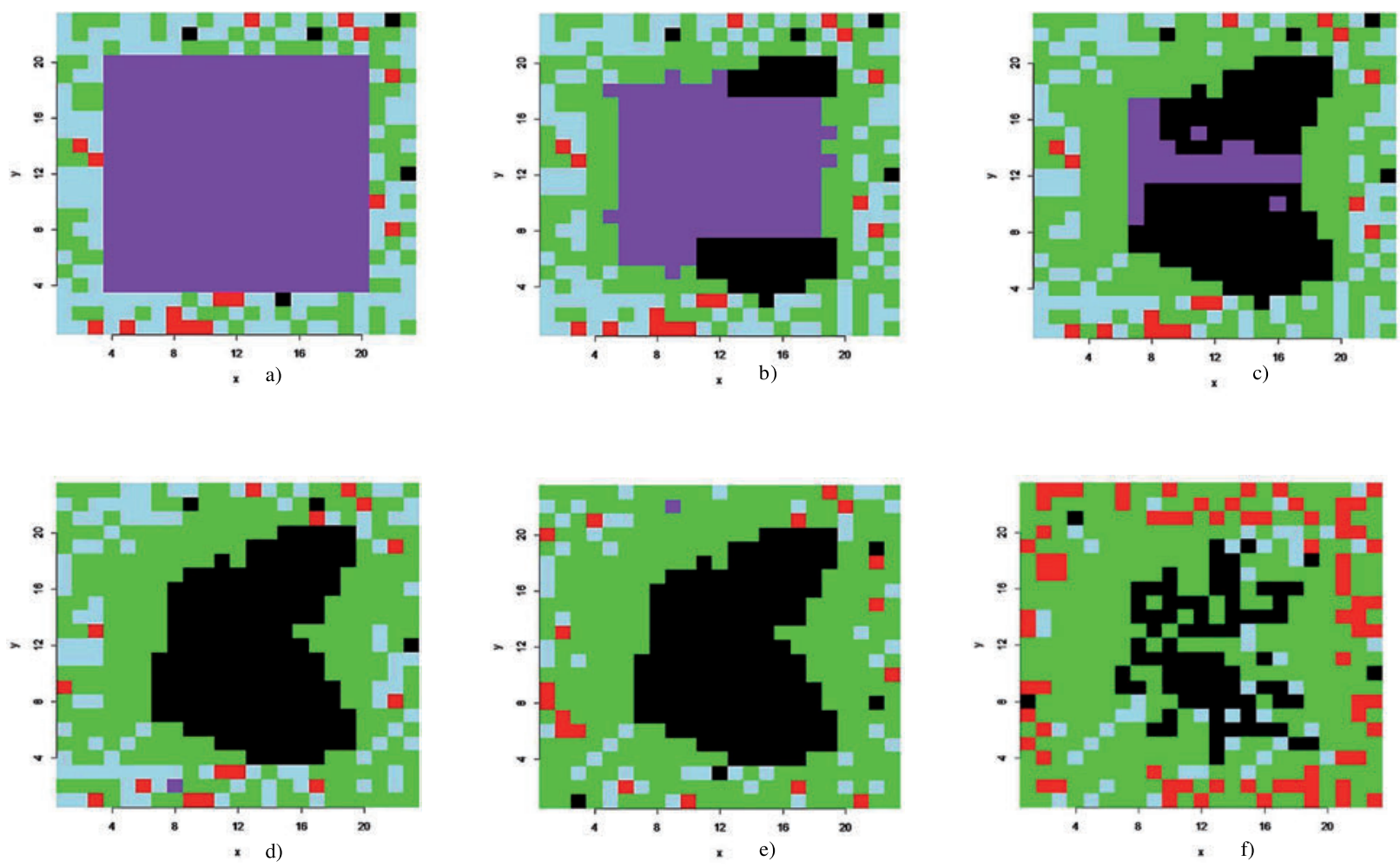

Figura 8. Escenarios de la dinámica de la comunidad de árboles del bosque mesófilo posterior a un disturbio de gran severidad. Iteraciones $\mathrm{a}=0, \mathrm{~b}=10, \mathrm{c}=20, \mathrm{~d}=30, \mathrm{e}=40 \mathrm{y} \mathrm{f}=100$. APT $=$ Azul; ASPT = Verde; AST = Rojo; ASPI = Rosa; VSI= Naranja; VSPI = Negro; celda vacía $=$ morado.

plántulas no se detectaron diferencias con respecto de la simulación base.

La dinámica posterior al disturbio de gran severidad evidenció que la recuperación de la vegetación es más lenta (el claro se cerró después de la iteración 20) y el tipo VSPI (perfil colonizador) es el que tiene una mayor participación en la colonización del claro. Asimismo, al finalizar la simulación, la abundancia de los tipos tolerantes a la sombra (APT, ASPT y AST) es ligeramente menor que la observada en el escenario final que se obtiene con el disturbio de intensidad ligera. El banco de semillas tarda un poco más en recuperarse que la comunidad de árboles (es a partir de la iteración 40 que el patrón de la distribución de semillas es similar al observado en las simulaciones base y de disturbio de severidad ligera). El banco de plántulas también tarda para volver a establecerse en la zona perturbada (a partir de la iteración 30 se presentan plántulas en toda la zona perturbada) y se distingue porque las plántulas del tipo VSPI se distribuyen en un mayor número de celdas en comparación con lo observado en las otras dos simulaciones.

Estos resultados sugieren que la recuperación del bosque después de un disturbio de gran intensidad es en cierta forma por pulsaciones. En primer término, los espacios abiertos por el disturbio y colindantes a las áreas no perturbadas son colonizados por semillas dispersadas de la vecindad, al germinar las semillas se originan juveniles que se establecen en esos sitios. Cuando estos nuevos individuos alcanzan la edad reproductiva, producen semillas que arribarán a otras áreas perturbadas colindantes a las áreas recién regeneradas y de esta manera se produce un nuevo pulso de colonización. Este patrón de recuperación del bosque también explica el desfasamiento en la recuperación de los subsistemas banco de semillas y de plántulas, dado que en cada pulso de regeneración, la llegada de semillas a los sitios perturbados depende de que previamente se establezcan juveniles y alcancen la edad reproductiva.

Los patrones de recuperación de la vegetación que se producen con el AC concuerdan con la respuesta que se ha previsto para disturbios de distinta intensidad: en disturbio ligeros se espera una rápida recuperación por el establecimiento de nuevos individuos a partir de los bancos de plántulas y semillas pre-existentes (Guariguata y Ostertag, 2001); mientras que en disturbios severos se prevé una recuperación lenta de la vegetación ya que la colonización depende de la disponibilidad de propágulos en sitios aledaños (Martínez-Ramos y García-Orth, 2007, Zimmerman et al., 2000). Asimismo, en estudios realizados en terrenos abandonados, se ha reportado la recuperación de una estructura similar a la de un bosque mesófilo maduro después de un lapso de 40-50 años (Muñiz-Castro et al., 2006). La concordancia entre las tendencias que se obtienen de las simulaciones y este registro en una comunidad, sugiere que el AC desarrollado es una 
herramienta que reproduce de manera aceptable la dinámica observada de la regeneración del bosque mesófilo.

Los patrones de colonización de las áreas perturbadas (los tipos APT y ASPT predominan en el disturbio de severidad ligera y el tipo VSPI en el de gran severidad) sugieren que existe una complementariedad en la respuesta a la intensidad del disturbio entre los tipos de regeneración: los sitios severamente perturbados son recolonizados por tipos intolerantes a la sombra y con semillas dispersadas por el viento (en la simulación realizada el tipo VSPI era el único tipo disponible); mientras que en sitios en los que se presenta un disturbio ligero se prevé que sean colonizados principalmente por tipos tolerantes a la sombra y con dispersión baro- endozoocora (en la simulación la colonización corrió a cargo de los tipos APT y ASPT). "La huella del disturbio" que se reveló en la simulación del disturbio de gran severidad es evidencia de la gran influencia que estos eventos tienen en la estructura y composición de las comunidades (White y Jentsch, 2001).

La diversidad de respuestas al disturbio en las comunidades (tipos de regeneración) tiene una importancia crucial para el renuevo y reorganización de las comunidades después de un disturbio (Díaz y Cabido, 2001). En este contexto, la exclusión de tipos funcionales con perfil colonizador que se presenta en las comunidades al final de la dinámica base sugiere que esas comunidades son más vulnerables a disturbios severos, ya que su capacidad de responder a tales disturbios depende de un solo tipo de regeneración. Esta vulnerabilidad también implica un mayor riesgo de perder servicios ecosistémicos al ocurrir un disturbio severo al faltar en la comunidad elementos que pudieran compensar la función que dejarían de ejercer las especies que son vulnerables a tales disturbios.

La modelación realizada sugiere que la aproximación seguida provee una herramienta útil para profundizar en el entendimiento de los sistemas ecológicos y para comprender la influencia humana sobre el sistema ambiental. Cuando se combina con otros enfoques puede ayudar a predecir y explicar los cambios en los procesos, a identificar elementos o procesos clave o sensibles de los ecosistemas; o generar información que puede conducir al desarrollo de hipótesis que deban sujetarse a prueba.

\section{Conclusiones}

Los patrones de colonización observados en las áreas perturbadas, sugieren que existe complementariedad en la respuesta al disturbio entre los tipos de regeneración del bosque mesófilo, lo cual le permite hacer frente a disturbios de diferente severidad. Sin embargo, la exclusión de tipos funcionales con perfil colonizador que se observa al final de la simulación de la comunidad que no fue perturbada, sugiere que en esa condición las comunidades son más vulnerables en caso de ocurrir disturbios severos, ya que no cuentan con los tipos de regeneración tolerantes a disturbios de esa intensidad.

La incorporación de los subsistemas banco de semillas y banco de plántulas como fuentes de regeneración de la comunidad de árboles en el AC, significan un progreso para simular la dinámica del bosque mesófilo, ya que representan la disponibilidad de los elementos de regeneración en el sistema. Por la arquitectura con la que se construyó el modelo, puede ser adaptado para estudiar la dinámica de la vegetación con diferentes objetivos, como la respuesta de la comunidad ante diferentes patrones de disturbio o identificar los procesos o estructuras clave en la regeneración del bosque.

\section{Agradecimientos}

Agradecemos a la Red Ambiente y Sustentabilidad del Instituto de Ecología, A.C. por el apoyo brindado para este estudio. El primer autor reconoce el apoyo para la realización de esta investigación proporcionada por la Comisión Federal de Electricidad. Asimismo, agradecemos los comentarios constructivos de dos árbitros anónimos que mejoraron sustancialmente este trabajo.

\section{Literatura citada}

Aassine S. y El Jaï M.C. 2002. Vegetation dynamics modelling: a method for coupling local and space dynamics. Ecological Modelling 154:237-249.

Alvarez-Aquino C., Williams-Linera G. y Newton A.C. 2005. Disturbance effects on the seed bank of Mexican cloud forest fragments. Biotropica 37:337-342.

Balzter H., Braun P.W. y Köhler W. 1998. Cellular automata models for vegetation dynamics. Ecological Modeling 107:113125 .

Batty M. 2005. Cities and complexity. Understanding cities with cellular automata, agent-based models and fractals. The MIT Press. Londres.

Bruijnzeel L. 2001. Hidrology of tropical montane cloud forests: a reassessment. En Second International Colloquium on Hydrology and Water Management in the Humid Tropics, pp. 353-383.

Busing R.T. y Mailly D. 2004. Advances in spatial, individualbased modelling of forest dynamics. Journal of Vegetation Science 15:831-842.

Carey P.D. 1996. DISPERSE: A cellular automaton for predicting the distribution of species in a changed climate. Global Ecology and Biogeography 5:217-226.

Challenger A. 1998. Utilización y conservación de los ecosistemas terrestres de México. Pasado, presente y futuro. Comisión Nacional para el Conocimiento y Uso de la Biodiversidad, Instituto de Biología, UNAM, México.

Colasanti R.L., Hunt R. y Askew A.P. 2001. A self-assembling model of resource dynamics and plant growth incorporating plant functional types. Functional Ecology 15:676-687.

Connell J.H. 1978. Diversity in tropical rain forests and coral reefs. Science 199: 1302-1310.

Díaz S., Cabido M. y Casanoves F. 1999. Functional implications 
of trait-environment linkages in plant communities. En: Weiher E. y Keddy P. Eds. Ecological Assembly Rules: Perspectives, Advances, Retreats. pp 338-362, Cambridge University Press, Cambridge.

Díaz S. y Cabido M. 2001. Vive la différence: plant functional diversity matters to ecosystem processes. Trends in Ecology and Evolution 16:646-655.

Díaz-Perea F.J., Equihua M., Jaramillo V.J., Méndez-Ramírez I. y Fragoso C. 2014. Key attributes to the disturbance response of montane cloud forest trees: shade tolerance, dispersal mode and the capacity to form a seed bank. Annals of Forest Science 71:437-451.

Ellison A.M. y Bedford B.L. 1995. Response of a wetland vascular plant community to disturbance: a simulation study. Ecological Applications 5:109-123.

Fernández-Quiroga M.P. 2005. Estado del arte en modelación funcional-estructural de plantas. Bosque 26:71-79.

Guariguata M.R. y Ostertag R. 2001. Neotropical secondary forest succession: changes in structural and functional characteristics. Forest Ecology and Management 148:185-206.

Hogewed P. 1988. Cellular automata as a paradigm for ecological modeling. Applied Mathematics and Computation 27:81-100.

Horn H.S., Nathan R. y Kaplan S.R. 2001. Long-distance dispersal of tree seeds by wind. Ecological Research 16:877-885.

Hughes L., Dunlop M., French K., Leishman M.R., Rice B., Rodgerson L. y Westoby M. 1994. Predicting dispersal spectra: a minimal set of hypotheses based on plant attributes. Journal of Ecology 82:933-950.

Klimešová J. y Klimeš L. 2007. Bud banks and their role in vegetative regeneration - a literature review and proposal for simple classification and assessment. Perspectives in Plant Ecology Evolution and Systematic 8:115-129.

Laurance W.F., Nascimento H.E.M., Laurance S.G., Condit R., D'Angelo S. y Andrade A. 2004. Inferred longevity of Amazonian rainforest trees based on a long-term demographic study. Forest Ecology and Management 190:131-143.

Lavorel S., McIntyre S., Landsberg J. y Forbes T.D.A. 1997. Plant functional classification from general groups to specific groups based on response to disturbance. Trends in Ecology and Evolution 12:474-478.

Leija-Loredo E.G., Reyes-Hernández H., Fortanelli-Martínez J. y Palacio-Aponte G. 2011. Situación actual del bosque de niebla en el estado de San Luis Potosí México. Investigación y Ciencia 19:3-11.

Martínez-Ramos M. y Álvarez-Buylla E.R. 1998. How old are tropical rain forest trees? Trends in Plant Science 3:400-405.

Martínez-Ramos M. y García-Orth X. 2007. Sucesión ecológica y restauración de las selvas húmedas. Boletín de la Sociedad Botánica de México 80 (Suplemento):69-84.

Moloney K.A. y Levin S.A. 1996. The effects of disturbance architecture on landscape-level population dynamics. Ecology 77:375-394.

Muñiz-Castro M.A., Williams-Linera G. y Rey-Benayas J.M. 2006. Distance effect from cloud forest fragments on plant community structure in abandoned pastures in Veracruz, Mexico. Journal of Tropical Ecology 22:431-440.

Nathan R. 2006. Long-distance dispersal of plants. Science 313:786-788.

Naeem S., Loreau M. y Inchausti P. 2002. Biodiversity and ecosystem functioning: the emergence of a synthetic ecological fra- mework. En: Loreau M., Naeem S. y Inchausti P. Eds. Biodiversity and Ecosystem Functioning Synthesis and perspectives, pp. 3-11, Oxford University Press, Oxford.

Pausas J.G. y Lavorel S. 2003. A hierarchical deductive approach for functional types in disturbed ecosystems. Journal of Vegetation Science 14:409-416.

Peterson G., Allen C.R. y Holling C.S. 1998. Ecological resilence, biodiversity, and scale. Ecosystems 1:6-18.

Petzoldt T. y Rinke K. 2007. Simecol: An object-oriented framework for ecological modeling in R. Journal of Statistical Software 22:1-31.

Plotnick R.E. y Gardner R.H. 2002. A general model for simulating the effects of landscape heterogeneity and disturbance on community patterns. Ecological Modelling 147:171-197.

Price D.T., Zimmermann N.E., Van der Meer P.J., Lexer M.J., Leadley P., Jorritsma I.T.M., Schaber J., Clark D.F., Lasch P., McNulty S., Wu J. y Smith B. 2001. Regeneration in gap models: priority issues for studying forest responses to climate change. Climatic Change 51:475-508.

R Core Team. 2015. R: A language and environment for statistical computing. R Foundation for Statistical Computing, Vienna. $<$ http://www.r-project.org/>.

Ramírez-Angulo H., Ablan M., Torres-Lezama A. y Acevedo M.F. 2006. Simulación de la dinámica de un bosque tropical de los Llanos Occidentales de Venezuela. Interciencia 31:101-109.

Rydgren K., Økland R.H. y Hestmark G. 2004. Disturbance severity and community resilience in a boreal forest. Ecology 87:1906-1915.

Roxburgh S., Shea K. y Wilson J. B.2004. The intermediate disturbance hypothesis: patch dynamics and mechanisms of species coexistence. Ecology 85:359-371.

Rzedowski J. 1978. Vegetación de México. Limusa, México D.F.

Saldaña-Acosta A., Meave J.A., Paz H., Sánchez-Velásquez L.R., Villaseñor J.L.

Martínez-Ramos M. 2008. Variation of functional traits in trees from a biogeographycally complex Mexican cloud forest. Acta Oecologica 34:111-121.

Sarkar D. 2008. Lattice: Multivariate Data Visualization with R. Springer, Nueva York.

Shea. K, Roxburgh S.H. y Rauschert E.S.J. 2004. Moving from pattern to process: coexistence mechanisms under intermediate disturbance regimes. Ecology Letters 7:491-508.

Soares-Filho B. S., Couthino-Cerqueira C. G. y Lopes-Pennachin C. 2002. DINAMICA - a stochastic cellular automata model designed to simulate the landscape dynamics in an Amazonian colonization frontier. Ecological Modelling 154:217-235.

Soetaert K., Petzoldt T. y Setzer W.R. 2010. Solving differential equations in R: Package deSolve. Journal of Statistical Software $33: 1-25$.

Sosa V. y Puig H. 1987. Regeneración del estrato arbóreo en el bosque mesófilo de montaña. En: Puig H. y Bracho R. Eds. El Bosque Mesófilo de Montaña de Tamaulipas, pp. 107-131, Instituto de Ecología, México D.F.

Sousa W.P. 1984. The role of disturbance in natural communities. Annual Review Ecology and Systematics 15:353- 391.

Toledo-Aceves T., Meave J.A., González-Espinosa M. y Ramírez-Marcial N. 2011. Tropical montane cloud forest: current threats and opportunities for their conservation and sustainable management in Mexico. Journal of Environment Management 92:974-981. 
Walker B., Kinzig A. y Langridge J. 1999. Plant attribute diversity, resilence, and ecosystem function: The nature and significance of dominant and minor species. Ecosystems 2:95-113.

White P.S y Jentsch A. 2001. The search for generality in studies of disturbance and ecosystems dynamics. Progress in Botany 62:399-450.

Recibido: 2 de mayo de 2014

Aceptado: 15 de julio de 2014
Zavala M.A., Díaz-Sierra R., Purves D., Zea G.E. y Urbieta I.R. 2006. Modelos espacialmente explícitos. Ecosistemas 3:88-99. Zimmerman J.K., Pascarella J.B. y Aide T.M. 2000. Barriers to forest regeneration in an abandoned pasture in Puerto Rico. Restoration Ecology 8:350-360. 